\title{
La suspensión en prevención como medida cautelar en el proceso contencioso administrativo*
}

\author{
Suspension in Prevention as a Precautionary Measure \\ in Administrative Law Litigation \\ Recibido: 12 de octubre de 2008 - Revisado: 1 de noviembre de 2008 - Aceptado: 6 de noviembre de 2008
}

Julieta Arenas Ceballos ${ }^{* *}$

\section{Resumen}

La suspensión en prevención, como una de las medidas cautelares en el proceso contencioso administrativo en Colombia, tuvo en su primer proyecto legislativo un planteamiento de acción, mediante la cual los ciudadanos que tuvieran indicios graves de que se iban a producir actos, hechos u operaciones administrativas ilegales o inconstitucionales en perjuicio suyo, podían solicitar a la justicia contenciosa administrativa que impidiera que éstos se causaran. Así quedó prevista en el Artículo 153 del C.C.A., contenido en el Decreto Extraordinario 01 de 1984, en el Título XVII, de la suspensión provisional.

Este instrumento fue esencialmente una medida cautelar que evitaba que una actuación de la administración inconstitucional o ilegal, no susceptible de otro recurso, naciera a la vida jurídica y cuyo fin era prevenir un daño que se ocasionaría con tal actuación. Se diferenciaba de la otra medida cautelar de suspensión provisional, en que la actuación ya se había producido y culminado o concretado, y en ella el acto empezaba a producir efectos (Ibáñez Najar, 1985, pp. 93 - 107).

La suspensión en prevención fue derogada después de un corto período de aplicación judicial, ${ }^{1}$ lo que desde entonces ocasionó un vacío legal al no contarse con este importante instrumento procesal cautelar que permita al propio ciudadano detener preventivamente una actuación de la administración contraria a la Constitución o la ley.

Por último, tal suspensión afecta el desarrollo constitucional de la tutela judicial efectiva, concretamente en lo que se refiere a las medidas cautelares en el proceso contencioso administrativo, tema que tiene pendiente en gran parte, su desarrollo en el ordenamiento jurídico colombiano.

Palabras claves

Proceso contencioso administrativo, medidas cautelares, tutela judicial efectiva, tutela cautelar judicial, suspensión provisional y suspensión en prevención.

\footnotetext{
Abstract

The suspension in prevention, as a precautionary measure in administrative law litigation in Colombia, in its first bill was established as an action, by which, citizens who had serious evidence that they were going to be illegal or unconstitutional actions or operations to their detriment, they could prevent such actions or operations from happening by means of Administrative Law litigation. This was established by Article 153 of the C.C.A, (Colombian Administrative Statute) included in the Extraordinary Decree 01 of 1984, in Title XVII of the provisional suspension. This tool was essentially a precautionary measure that prevented an unconstitutional or illegal administrative action, not subject to any other legal action, from happening, and its purpose was to prevent any harm that would result from such action. It was different from other protection measure of temporary suspension in which the action had already happened and such action was already producing effects.

The suspension in prevention was revoked after a short period of judicial enforcement, resulting in a legal emptiness caused by the absence of this important procedural protection tool that allowed citizens to preventively stop administrative actions against the Constitution or the law.

Finally, such suspension affects the constitutional development of effective judicial protection, specifically as it relates to precautionary measures in administrative law litigation, issue that is to be hugely developed in the Colombian legal system.

Key Words

Administrative Law Litigation, precautionary measures, effective judicial protection, judicial precautionary protection, temporary suspension and suspension in prevention.
}

\footnotetext{
* Este artículo constituye un avance de investigación denominado: La suspensión en prevención como medida cautelar en el proceso contencioso administrativo, avalado por la Universidad Sergio Arboleda. Dirigido por Jorge Enrique Ibáñez Najar -Director e investigador del Grupo Justicia y DesarrolloCategoría A Colciencias.

** Abogada Universidad Santo Tomás, Especialista en Derecho de Seguros, Derecho Constitucional, Derecho Administrativo y, candidata a Magíster en Derecho, Universidad Sergio Arboleda. Investigadora del Grupo Crear de la Escuela de Derecho de la Universidad Sergio Arboleda. Categoría A Colciencias. Correo electrónico: julieta.arenas@usa.edu.co
} 


\section{Introducción}

Por una parte, la preocupación en el tema de las medidas cautelares en lo contencioso administrativo ha llevado al planteamiento de reformas de carácter legal (Ibáñez, 2007; Bacigalupo, 1999; Campo, 1997; García de Enterría, 1992; Chinchilla, 1991) que no hagan ilusorias las pretensiones de los particulares en las reclamaciones judiciales contra las actuaciones ilegales o inconstitucionales de la administración.

Como lo expresa Chinchilla:

"En efecto, la medida cautelar tiene sentido si hay un derecho que necesita protección provisional y urgente, a raíz de un daño ya producido o de inminente producción, mientras dure un proceso en el que se discute precisamente una pretensión de quien sufre dicho daño o amenaza. Sin este peligro que cautelarmente hay que frenar para que el objeto del proceso se mantenga íntegro durante el tiempo que dure, no hay medidas cautelares

La medida cautelar exige, por ello, como puso de relieve Calamandrei, un preventivo cálculo de probabilidad sobre el periculum in mora que no puede separarse de otro preventivo cálculo de probabilidad que es el que se hace sobre la existencia del derecho cuya tutela se solicita en los tribunales [fumus boni iuris]." (Chinchilla C, 1991, p.42)."

Es importante resaltar, conforme lo señala Calamandrei, que:

"La acción cautelar tiene como condición no la existencia de un derecho, sino la apariencia del derecho: y que, aun cuando el juicio sobre la acción cautelar se desarrolla con la garantía de la cognición ordinaria (ocurre, por ejemplo, en el juicio de convalidación del secuestro), esta cognición, aunque sea plena y a fondo, no va más allá, por lo que se refiere al derecho principal, de simple hipotética apariencia. Esto significa que, una vez considerada tal apariencia, la acción cautelar está, sin más, en relación al peligro, plena y definitivamente fundada; y si después, en el juicio principal se estableciera que la apariencia, antes tomada en consideración, del derecho no corresponde a la existencia del mismo, esto serviría para demostrar que es infundada la acción principal (entre las condiciones de la cual figura precisamente la de la existencia del derecho), pero no para demostrar retroactivamente la falta de fundamento de la acción cautelar y la ilegitimidad de la medida cautelar, la cual, como se ha dicho, tiene precisamente el oficio normal y fisiológico de proveer interinamente mientras el derecho es todavía incierto (supuesto, pero incierto) y de permitir así que el juicio principal, encaminado a eliminar tal falta de certeza, se desenvuelva sin precipitación”( Calamandrei, 1945, p. 83).

De otra parte, la constitucionalización del derecho en el caso de la cautela judicial o medida cautelar, se deriva de la tutela judicial efectiva, derecho fundamental previsto en la mayoría de los ordenamientos constitucionales modernos, entre otros Colombia, España, Alemania, México y Chile, que resaltan la importancia en el contexto jurídico de este derecho, que ha evolucionado hasta alcanzar la denominación de fundamental ${ }^{2}$, al igual que en los tratados internacionales de derechos humanos ${ }^{3}$ y de lucha contra la corrupción ${ }^{4}$, que garantizan no solamente el acceso a la administración de justicia, sino que este acceso sea oportuno y eficaz. Así, al desarrollarse jurisprudencialmente esta institución jurídica, la Corte Constitucional Colombiana ${ }^{5}$ ha construido las características del derecho al acceso a la administración de justicia (Moreno, 2000), para lo cual ha señalado que se trata de un derecho fundamental; libre, ejercido directamente o por medio de representante judicial; ser regulado por la ley, que exige una decisión judicial pronta y cumplidamente y, además, válida, veraz, correcta y útil. Para que el acceso a la administración de justicia sea efectivo, reclama una conducta del juez, que al analizar el caso, pondere responsablemente las situaciones que se someten a su juzgamiento y donde no se debe exigir más procedimientos que los idóneos, sujetos a las reglas de derecho, con la debida oportunidad, para obtener una decisión judicial. ${ }^{6}$

\section{Problema de investigación}

La suspensión en prevención, como medida cautelar, fue un instrumento previsto para evitar 
una actuación inconstitucional o ilegal de la administración pública, con la cual el ciudadano tenía una manera oportuna y eficaz de defender sus derechos y así se evitaban los consabidos y largos procesos contra la Administración y las cuantiosas indemnizaciones a cargo del Estado.

Esta figura jurídica cautelar fue presentada inicialmente en 1980 ante el Congreso de la República como una acción preventiva, para lograr mayor eficacia de la suspensión provisional, tomando las experiencias de las acciones similares contempladas en los ordenamientos jurídicos de Argentina y México como el "amparo" y en el sistema anglosajón con las "injuctions".

Por ello, el memorando al Congreso de la República que ampliaba la exposición de motivos del proyecto, anotaba: "Este proyecto busca crear acciones que sirvan para prevenir la violación de la ley, impedir daños a las personas, evitar indemnizaciones a cargo de los presupuestos públicos, reducir el número de litigios administrativos" (Ibáñez Najar, 1985, p. 93).

Más adelante, "el Código de 1984 introdujo la suspensión provisional en prevención contra los actos preparatorios o de trámite cuando se dirigieran a producir un acto definitivo inconstitucional o ilegal que no sería susceptible de ningún recurso o contra los actos de ejecución cuando el definitivo no hubiere sido notificado legalmente; cuando los recursos interpuestos contra él no hubieren sido resueltos ni siquiera en forma presunta o cuando las autoridades hubieren impedido que se recurriera. Entonces, la suspensión en prevención impediría completar o ejecutar los actos definitivos". (Ibáñez Najar, 2007, p. 819).

Sin embargo, la suspensión en prevención tuvo un corto y no muy afortunado desarrollo judicial $^{7}$, toda vez que fue derogada parcialmente por la sentencia No. 48 del 10 de agosto de 1989, de la Corte Suprema de Justicia, Sala Plena, proferida dentro del Expediente 1922 y posteriormente derogada expresamente por el artículo 68 del Decreto Extraordinario 2304 de 7 de octubre de 1989.
¿Se justificaba derogar la figura de la suspensión en prevención que ya había sido incorporada en el ordenamiento jurídico en 1984, y que se aplicó hasta 1989? ¿Se requiere revivir esta figura y de nuevo consagrarla en el derecho colombiano?

Sin embargo, los particulares a pesar de contar con mecanismos de control de legalidad y de constitucionalidad de estos actos, no logran el restablecimiento de sus derechos y la reparación de los daños irrogados por la administración de manera justa y oportuna, principalmente por el funcionamiento defectuoso de la administración de justicia relacionado con la congestión y la mora judicial. Correlativamente, por la misma causa, en aquellos casos en que es condenado el Estado, el valor de las reparaciones e indemnizaciones por los comportamientos citados de sus agentes va creciendo de tal manera que durante el proceso judicial los pasivos contingentes constituyen un grave problema para los presupuestos públicos que tienen vigencia anual y luego, cuando se liquidan las condenas, éstas son tan altas que los recursos que deben destinarse para cumplirse son insuficientes, al tiempo que por virtud de las mismas, el Estado debe disminuir, paulatinamente, los recursos destinados para la ejecución de la política social y el bienestar de la comunidad.

Además, la responsabilidad de la actuación pertinente de los funcionarios involucrados, con el paso del tiempo y la definición jurisdiccional se vuelve inoperante, teniendo en cuenta que los funcionarios del nivel ejecutivo son, en la mayoría de los casos, de libre nombramiento y remoción, por lo que, en la realidad al momento de un fallo judicial, quien realmente responde pecuniariamente es el Estado, no obstante la consagración y desarrollo legal de la acción de repetición que tan buenos propósitos tiene, pero de resultados ineficaces.

No basta la existencia de un aparato judicial permanente si él no es oportuno, eficiente y eficaz. No basta la consagración de un elenco de acciones judiciales si ellas sólo pueden ejercitarse 
después de producido el acto manifiestamente ilegal o inconstitucional o de producido el hecho dañoso, el desvío o el abuso de poder. Y, no basta la consagración de la posibilidad de solicitar la suspensión provisional de los efectos del acto, pues para que se pueda pedir, es menester que el acto exista y se pruebe siquiera sumariamente y sin mayor esfuerzo que él es groseramente inconstitucional o ilegal o que fue expedido con grosero abuso o desvío de poder.

\section{Metodología}

Con base en la clasificación tradicional, la investigación jurídica acude a normas jurídicas, jurisprudencia y doctrina referente al tema de la suspensión en prevención, donde inicialmente se considerará dentro de un estudio comparativo, la suspensión provisional prevista en el actual ordenamiento legal colombiano.

La estrategia metodológica se guía por la investigación histórica de antecedentes tanto constitucionales, legales y jurisprudenciales en los últimos veinticinco años.

La investigación utiliza también el tipo explicativo en cuanto intenta buscar un mejor resultado en la solución de los inconvenientes de carácter constitucional y legal presentados en el desarrollo de la actividad administrativa, haciendo que se evite culminar una actuación administrativa de la cual surja un acto inconstitucional, ilegal o abusivo o que simplemente constituya una vía de hecho de la Administración, y que no se presente, un extenso, fatigoso y cuantioso proceso judicial que ocasiona a la postre grandes perjuicios económicos tanto al erario público como a los particulares.

Lo más importante es lograr evidenciar la necesidad de solucionar por lo menos uno de los problemas más graves, en nuestra administración de justicia de lo contencioso administrativo -en este caso- que es la justicia retardada e ineficaz, que a la postre es considerada como denegación de justicia. Lo anterior sustentado en estadísticas que provienen no solo de los organismos estatales ${ }^{8}$ que tienen ese deber legal, sino también en organismos internacionales ${ }^{9}$ que de manera directa o transversal, analizan la problemática de la administración de justicia, como factor de garantía del ejercicio de los derechos humanos fundamentales, base del desarrollo de las instituciones democráticas y aún del control de la corrupción, en un contexto constitucional de Estado Social de Derecho.

Se ha presentado un interés especial en los últimos años en buscar las posibles soluciones para atender la problemática derivada del desmesurado atraso en la resolución de los procesos judiciales, en especial, en la justicia de lo contencioso administrativo. Es un tema de preocupación constante, que como se ha observado persiste no sólo en el entorno local sino mundial.

García de Enterría al referirse a la situación de la justicia administrativa prevé:

"La tendencia al incremento de los procesos contencioso-administrativos "es perfectamente común en los Estados occidentales. No se trata, pues, de ninguna moda o fenómeno ocasional, tras del cual quepa esperar un retorno más o menos lejano a la antigua y tranquila quietud, sino de algo consolidado y definitivo cuya tendencia se incrementará aún en el futuro. La tendencia hacia una más extensa justicia administrativa se enraíza en lo más profundo de las sociedades democráticas, y es ella misma una de las expresiones más seguras del propio principio democrático, en cuanto que se inserta en el núcleo de la técnica del gobierno por la ley y no por los caprichos de los hombres. Es un desarrollo de la conciencia ciudadana, que es la titularidad común del poder público, lo que hace presente en el justiciable que reclama ante el Tribunal contra la Administración por presunta ilegalidad de su actuación. Ese sentimiento fácilmente previsible que seguirá en expansión creciente como una consecuencia de mayor conciencia democrática, como Tocqueville previó lúcidamente hace ya siglo y medio, y como demuestra la experiencia uniforme de todos los países democráticos. Es lo que se ha llamado "un 
contencioso-administrativo de masas". (García de Enterría, 2000, p. 256).

En Colombia, el Profesor Jorge Enrique Ibáñez Najar se refiere a los aspectos positivos que ha tenido el Código Contencioso Administrativo contenido en el Decreto 01 de 1984, pero también indica la posibilidad de plantear reformas al mismo, de acuerdo con la realidad de hoy para precaver y resolver los conflictos entre la Administración y los particulares de una manera oportuna, eficaz y eficiente. (Ibáñez Najar, 2007, p. 819).

Al referirse a la creación de la suspensión en prevención en el C.C.A., contenido en el Decreto 01 de 1984, el profesor Ibáñez Najar señala:

\begin{abstract}
"Mientras que la solicitud de suspensión provisional debe presentarse conjunta o simultáneamente con la acción de nulidad o la de nulidad y restablecimiento o antes de dictarse el auto admisorio contra un acto administrativo ya expedido y que está produciendo efectos, el Código de 1984 introdujo la suspensión provisional en prevención contra actos preparatorios o de trámite cuando se dirigieran a producir un acto definitivo inconstitucional o ilegal que no sería susceptible de ningún recurso o contra los actos de ejecución cuando el definitivo no hubiere sido notificado legalmente, cuando los recursos interpuestos contra él no hubieran sido resueltos ni siquiera en forma presunta o cuando las autoridades hubieran impedido que se recurriera. Entonces, la suspensión en prevención impediría completar o ejecutar los actos definitivos" (Ibáñez Najar, 2007, p. 819).
\end{abstract}

Se observa, que son escasas las propuestas de reforma contenciosa administrativa en Colombia, sustentadas en la tutela cautelar judicial, tan necesaria para lograr la eficacia en esta justicia especial.

Sin embargo, el profesor Manuel Restrepo ha planteado:

“...que si bien es cierto que la ley ha de prever la existencia, posibilidad de operancia y casos en que tienen ocurrencia las medidas cautelares, en observancia al principio de legalidad, para una mejor garantía de los derechos que pueden verse afectados por la demora en el trámite de los procesos judiciales, especialmente dentro del marco garantista de la Carta Política vigente-Colombiana-resulta ineficiente la regulación actual de la tutela cautelar judicial, concebida en forma taxativa, de manera que solamente tienen carácter cautelar aquellas medidas establecidas en una regla jurídica (...). Se impone la introducción en el ordenamiento jurídico nacional de una norma en blanco que permita la adopción de cualquier medida cautelar que se presente como idónea para la salvaguarda del objeto litigioso y la ejecución in natura de la sentencia, dejando al juez en libertad de otorgar aquéllas cuyo discernimiento le indique que son las más convenientes (Restrepo, 2005, pp. 17,18).

En consecuencia, en Colombia la única medida cautelar existente en el proceso contencioso administrativo es la suspensión provisional de los efectos del acto administrativo demandado, lo que reclama, de manera urgente, una ampliación del elenco de medidas cautelares para las situaciones no contempladas como la inactividad de la administración, o actos positivos de la misma ${ }^{10}$, para superar de alguna manera la situación actual de ineficiencia en la justicia administrativa.

El término de medida cautelar, en el sentido amplio (De la Sierra, 2004, p.42) se entienden como el sinónimo de todos los instrumentos procesales aptos para adoptar resoluciones rápidas. A su vez en el sentido estricto, el término hace referencia a medias instrumentales que pueden ser definidas por el juez en el proceso para proteger provisionalmente los bienes, derechos o intereses de las partes y de esta manera evitar que la resolución final del proceso se vea desprovista de objeto. En el ordenamiento jurídico español el Juez contenciosos-administrativo (Parejo, 2003, p.1195) puede dispensar una tutela cautelar en los términos en todo equivalentes a la otorgable por el juez civil, sin otras modulaciones ${ }^{11}$ que las que resultan justamente de la peculiaridad o especialidad de la jurisdicción que el primero ejerce.

En ese orden de ideas, la cuestión debatida por los procesalitas, civiles principalmente, sobre 
la naturaleza jurídica de la tutela cautelar, se ha enfocado en determinar si es un proceso autónomo distinto del proceso declarativo o ejecutivo, o por el contrario, el considerar dicha figura como una etapa instrumental de los mismos carente de cualquier autonomía procesal.

El proceso cautelar como proceso autónomo, fue desarrollado principalmente en Italia (Chiovenda, 1954 ${ }^{12}$; Rocco ${ }^{13}, 1974$; Liebman, $1980^{14}$ ), seguido en España, en donde Cortés Domínguez (citado por Chinchilla, 1991, p.52) expresa al respecto:

“...el punto de partida es la existencia de un verdadero y puro derecho procesal a la cautela (autónomo), es decir, el aseguramiento de la tutela plena de las sentencias (...). Del carácter accesorio y dependiente de la cautela en relación a la sentencia declarativa, no se deriva la negación de la autonomía del proceso cautelar que, por el contrario, se fundamenta en que las medidas cautelares se adoptan bajo los presupuestos procesales y con un procedimiento distinto al principal".

El término de "proceso cautelar" (De la Sierra, 2004, p.43), es pues utilizado por quienes consideran la función cautelar como un proceso autónomo, instrumental y diferenciado de los procesos declarativo y ejecutivo, donde la pretensión cautelar no consiste en declarar el derecho ni de realizarlo forzosamente, sino proteger determinadas situaciones jurídicas con los mecanismos previstos en el ordenamiento jurídico, en tanto se adopte la resolución de fondo.

La verdad (García Sarmiento, 1981, p.12) "es que, examinado el derecho que la norma jurídica confiere a toda persona que crea fundamentalmente que periculum in mora puede sufrir perjuicios (para pedir en consecuencia, cumpliendo las formalidades de la ley la medida de cautela), se trata de una acción con caracteres propios que necesariamente no tiene un fin en sí misma, no es cautela por cautela, pero sí respecto a la facultad jurídica de exigir al Estado un derecho autónomo y, por lo tanto una acción de cautela".
De otra parte el término "medidas cautelares" (De la Sierra, 2004, p.43), debía aplicarse si la concepción que se defiende es la de una concatenación de actos independientes y no reconducibles a una unidad. En este caso, las medidas cautelares no aparecerían, en principio, como un proceso autónomo, sino como un incidente del proceso declarativo o como medio de aseguramiento del proceso ejecutivo.

Para Calamandrei (citado por Chinchilla, 1991, p.52), la tutela cautelar carece de "una característica y constante estructura exterior". En una palabra, de una autonomía procedimental que para él parece ser la clave para afirmar o negar su autonomía procesal. Por ello, el procesalista florentino advertirá en las primeras páginas de su Introduzione allo Studio Sistematico dei Provvedimenti cautelari que el objeto de su estudio no va a ser el proceso cautelar, sino el "provvedimento", puesto que el proceso que pone en marcha una medida cautelar no tiene una característica y constante estructura exterior.

Es, pues, para los procesalistas, considerado el proceso cautelar (Azula, 1982, p.69), como las medidas que tienden a garantizar los resultados que persigue en otro. Lo que significa en este caso que el proceso cautelar es de carácter accesorio, puesto que está condicionado o supeditado a la existencia de otro, y corre por tanto la misma suerte de éste, agregando su peculiaridad de medio instrumental para obtener la efectividad de los resultados queridos.

Devis Echandía (1993, p.209) lo considera como proceso y como acción cautelar, definiéndolo como derecho de iniciar un procedimiento para que se adopten medidas judiciales necesarias para el aseguramiento de la satisfacción del derecho material o para su defensa; es decir, que se realice un proceso cautelar.

Esta acción cautelar puede ser autónoma, es decir, independiente de otra que posteriormente se ejerza para un nuevo proceso, pero por lo general es accesoria o independiente de otra, 
como a la que persigue medidas cautelares previas a la ejecución, visión prevista por Carnellutti (1944), en relación del proceso cautelar con el proceso definitivo que conduce a separar el proceso cautelar como autónomo y el proceso cautelar dependiente.

En posición contraria a la concepción de autonomía procesal de las medidas cautelares están Fernández y Serra Domínguez citados por Chinchilla, 1991, pp. 53-56. El primero define las medidas cautelares por su instrumentalidad, que las hace pertenecer a la ejecución forzosa, que en definitiva no son sino un adelanto de parte de las actuaciones que forman la ejecución futura; el segundo autor reconoce que algunas medidas cautelares deben tramitarse en pieza separada, pero eso es una autonomía procedimental no suficiente para construir un nuevo tipo de proceso.

Chinchilla (1991, p.55) se inclina por la corriente que considera al proceso una unidad de la que la tutela cautelar, cognición y ejecución serían diversas etapas. En esta unidad que es el proceso, la tutela cautelar, como puso de relieve Calamandrei, puede tener, según los casos, efectos declarativos o ejecutivos, junto a su característica principal y propia, consistente en proteger preventiva y provisionalmente los derechos e intereses legítimos del demandante, adelantando, en cierta medida, el juicio declarativo y posterior ejecución de la sentencia.

Llama la atención que las medidas cautelares en el contencioso administrativo, aglutinan en unas $\mathrm{u}$ otras palabras una necesidad expresada por los doctrinantes en principio y después manifestada en la jurisprudencia, especialmente de los Tribunales Europeos, tanto nacionales como de la Unión, donde la inaplazable reconstrucción “(...) del sistema legal no debería limitarse, sin embargo, -en razón de la apertura jurisprudencial en Europa de las medidas cautelares- a una nueva regulación de la suspensión en línea que dicha jurisprudencia marca, sino que habría que concretarse, también a la vista de ella, en la admisión formal de otras medidas cautelares distintas y más efectivas que la mera y simple suspensión enderezadas, al igual que ésta, a garantizar el derecho fundamental a la tutela cautelar- garante de la tutela efectiva final-." (García de Enterría y Fernández, 1997, p 622).

\section{Comentario crítico}

El debate principal se centra en la ineficacia de las medidas cautelares previstas en el proceso contencioso administrativo en Colombia, que hace que las mismas se tornen inoperantes, y demande la necesidad de abrir las posibilidades de más instrumentos cautelares en el proceso contencioso administrativo, que proporcionen más prontitud y eficacia a quien demanda justicia.

El problema de la congestión judicial en todos los niveles es notorio. Ni aun con la ampliación de las acciones constitucionales en el año 1991 para garantizar, proteger y efectivizar los derechos fundamentales de los ciudadanos y además de los derechos colectivos, se tiene que la tutela judicial o acceso efectivo a la administración de justicia, se ha podido avanzar para que se pueda resolver efectivamente la problemática aquí planteada.

En la jurisdicción contencioso administrativa, es aún más dramática dicha congestión, no obstante que las cifras estadísticas con las que se cuenta no determinan de ninguna manera la situación real, son dispersas, y, no cuentan con una sistematización puntual en la que se mida, por ejemplo la aceptación o no de una medida tan importante como la suspensión provisional de los efectos de los actos administrativos, -en principio seriamente cuestionados en su constitucionalidad o legalidad por parte de los ciudadanos.

Cierto es que los actos administrativos gozan del principio de legalidad y ejecutoriedad, para una eficacia pretendida de las actuaciones administrativas y para alcanzar el fin propuesto, pero también es cierto, que los abusos constantes del poder y actuaciones desmedidas de la 
administración, hacen que el ciudadano común no se pueda defender o hacer valer sus derechos de manera eficaz, entendiendo esa eficacia como una actuación cumplida en la justicia especial contencioso administrativa -en términos reales de tiempo- y que cuando se llegue al momento de la sentencia, debidamente ejecutoriada, que no sea la solución oportuna a la controversia mucho tiempo atrás planteada a la jurisdicción.

Ahora bien, no se separa de la realidad actual el tema de las medidas cautelares en la justicia contencioso administrativa, pues la globalidad de los compromisos jurídicos atañe a la órbita de nacional de los Estados, en cuanto a sus compromisos internacionales, bien sea de carácter privado o público. Es por eso que un sistema de medidas cautelares más abierto, puede fortalecer el papel de la institución jurisdiccional en la resolución de los grandes conflictos que envuelven grandes intereses no sólo económicos sino a la postre políticos. Por tanto y de cara a la imagen mundial, es igualmente importante insistir en este punto.

Deben plantearse reformas procedimentales soportadas en serios estudios casuísticos de los factores que más inciden en las razones presentes que ocasionan que los procesos no obtengan soluciones rápidas, oportunas y por supuesto legales, y además, insistir en que el sustento constitucional de la tutela judicial, como derecho fundamental, ya ha tenido un desarrollo importante en nuestro país y en el mundo entero para no disculpar más su falta de instrumentación legal, por lo menos en lo que respecta a las medidas cautelares en lo contencioso administrativo.

Las actuaciones en que se ve implicada la Administración son cada vez más complejas y comprometen cada vez más la estabilidad socioeconómica del país, por eso debe darse cuenta de que es absolutamente insuficiente e ineficiente la sola suspensión provisional de los actos administrativos como medida cautelar actual dentro del proceso.
Como lo expone con razón, Alejandro Nieto (2003, p. 24):

\begin{abstract}
"Las leyes, la jurisprudencia y la doctrina se retroalimentan en un proceso circular indefinidamente repetido: las leyes cristalizan los conceptos doctrinales y los autores se apoyan en las leyes, pero siempre con un telón judicial de fondo que actúa como piedra de toque de cuanto los textos establecen. Gracias a los conceptos el jurista nunca está abandonado y puede operar de una manera rápida y eficaz, puesto que, cuando analiza un fenómeno jurídico real que carece de regulación legal, lo único que necesita es subsumirlo dentro de un tipo y, una vez realizada esta operación personal, las consecuencias jurídicas vienen por sí solas, ya que están predeterminadas en el concepto abstracto."
\end{abstract}

\section{Conclusiones}

No cabe la menor duda que en el desarrollo de la actividad administrativa a cargo de los diferentes órganos que integran la administración pública, se comenten muchos errores con la expedición de actos inconstitucionales o ilegales, o se incurre en arbitrariedades, abuso o desvío de poder, incluso en vías de hecho. En consecuencia, lo que debe hacerse es precaver y evitar una conducta irregular, desviada o abusiva, o la expedición de un acto manifiestamente ilegal o inconstitucional y, así evitar un proceso judicial, del cual, por lo general no sale bien librado ni el particular, ni la Administración Pública. Es por ello que debería volver a existir en el derecho colombiano, la consagración de la suspensión en prevención de la actuación administrativa.

El mundo actual se encuentra entrelazado por un sin número de situaciones de orden legal cada vez más complejas, por lo que los ordenamientos jurídicos nacionales deben estar siempre atentos a asumir esas situaciones. El problema de la justicia atrasada -que no tendría el carácter de justicia como tal- es una situación grave para las democracias latinoamericanas, con estudios tan serios y meticulosos como el presentado por el Banco Interamericano de Desarrollo en 2007 referido en la introducción de este capítulo, donde 
se evidencia, entre otras cosas, la falta de sistematización de la información de los procesos, sus avances y su eficacia.

De igual manera, en el documento CONPES No. 3250 de $2003^{15}$, el Consejo Nacional de Política Económica y Social señala las líneas de acción para el fortalecimiento de la defensa legal de la Nación y evidencia, que no se sabe a ciencia cierta, ni siquiera cuántos, cuáles y en qué condiciones existen procesos judiciales en contra de la Nación, lo que además hace urgente tomar medidas de carácter normativo, para al menos evitar tantas actuaciones ilegales o inconstitucionales de los entes administrativos.

En ese orden de ideas y para finalizar, la investigación jurídica debe enfocarse en plantear la mejor solución jurídica posible a la problemática real, de tal suerte que dote al ordenamiento jurídico de normas eficaces y no de simples legislaciones coyunturales que tienden a visualizar solamente la solución de problemas individuales o de colectivos de ciudadanos en casos muy particulares.

\section{Notas}

${ }^{1}$ Derogada mediante el Artículo 68 del Decreto Extraordinario 2304 de 1989.

${ }^{2}$ En Colombia el Preámbulo y artículos 2, 228 y 229 de la Constitución Política prevé que: "Se garantiza el derecho de toda persona para acceder a la administración de justicia. La ley indicará en qué casos podrá hacerlo sin representación de abogado". En España en el artículo 24.1 de la Constitución dice que: "Todas las personas tienen derecho a obtener la tutela efectiva de los jueces y los tribunales en el ejercicio de sus derechos e intereses legítimos, sin que, en ningún caso, pueda producirse indefensión.”. En Alemania en el Artículo 103.1 de la Constitución señala que: "Todos tienen el derecho de ser oídos ante los tribunales.". En Italia en el artículo 24.1 de la Constitución consagra que: "Todos podrán acudir a los Tribunales para la defensa de sus derechos y de sus intereses legítimos". En México en el artículo 17 de la Constitución reza que: "Artículo 17. Ninguna persona podrá hacerse justicia por sí misma, ni ejercer violencia parar reclamar su derecho. Toda persona tiene derecho a que se le administre justicia por tribunales que estarán expeditos para impartirla en los plazos y términos que fijen las leyes, emitiendo sus resoluciones de manera pronta, completa e imparcial. Su servicio será gratuito, quedando, en consecuencia, prohibidas las costas judiciales. Las leyes preverán mecanismos alternativos de solución de controversias. En la materia penal regularán su aplicación, asegurarán la reparación del daño y establecerán los casos en los que se requerirá supervisión judicial. Las sentencias que pongan fin a los procedimientos orales deberán ser explicadas en audiencia pública previa citación de las partes. Las leyes federales y locales establecerán los medios necesarios para que se garantice la independencia de los tribunales y la plena ejecución de sus resoluciones. La Federación, los Estados y el Distrito Federal garantizarán la existencia de un servicio de defensoría pública de calidad para la población y asegurarán las condiciones para un servicio profesional de carrera para los defensores. Las percepciones de los defensores no podrán ser inferiores a las que correspondan a los agentes del Ministerio Público. Nadie puede ser aprisionado por deudas de carácter puramente civil." En Chile en el Artículo 19.3 de la Constitución Política dispone: "Toda persona tiene derecho a defensa jurídica en la forma que la ley señale y ninguna autoridad o individuo podrá impedir, restringir o perturbar la debida intervención, del letrado, si hubiere sido requerida..."

${ }^{3}$ En la Declaración Universal de Los Derechos Humanos, adoptada por la Asamblea General de Naciones Unidas el 10 de diciembre de 1948, en su Artículo 8 prevé: “Toda persona tiene derecho a un recurso efectivo ante los tribunales nacionales competentes, que la ampare contra actos que violen sus derechos fundamentales reconocidos por la constitución o por la ley." Accesible en: http://www.un.org/ spanish/aboutun/hrights.htm . En la Convención 
Americana de Derechos Humanos, Pacto de San José de Costa Rica, en su Artículo 8.1 dispone:"Garantías Judiciales 1. Toda persona tiene derecho a ser oída, con las debidas garantías y dentro de un plazo razonable, por un juez o tribunal competente, independiente e imparcial, establecido con anterioridad por la ley, en la sustanciación de cualquier acusación penal formulada contra ella, o para la determinación de sus derechos y obligaciones de orden civil, laboral, fiscal o de cualquier otro carácter". Accesible en: http://www.oas.org/Juridico/ spanish/tratados/b-32.html. entre otros.

${ }^{4}$ PNUD 2004, Informe Anticorrupción, accesible en: http://www.undp.org/governance/ docs/AC_PN_Spanish.pdf, recuperado el 20 de junio de 2008.

${ }^{5}$ Sentencias de la Corte Constitucional sobre el derecho al acceso a la administración de justicia entre otras: C-426 de 2002; C-1171 de 2005 y C483 de 2008.

${ }^{6}$ Véase el interesante estudio realizado por Luis Javier Moreno Ortiz, sobre las Sentencias de la Corte Constitucional referentes al acceso a la administración de justicia, entre otras, C-544 de 1992; T320, T-329 y T-431 de 1993; T-171, T-172, T-231, T-239 y C-351 de 1994; T-067 y C-179 de 1995; T-298 de 1997. Moreno Ortiz Luis Javier, Acceso a la justicia, Ediciones Academia Colombiana de la Jurisprudencia Colección Portable, Bogotá D.C., 2000, pp. 108-128.

${ }^{7}$ Entre otras sentencias en que prosperó la suspensión en prevención, véanse: Consejo de Estado, Sala de lo Contencioso Administrativo, Sección Primera, Radicación No. 830, providencia del 23 de marzo de 1988. Consejo de Estado, Sala de lo Contencioso Administrativo, Sección Primera, Radicación Número 862, providencia del 4 de abril de 1988. Consejo de Estado, Sala de lo Contencioso Administrativo, Sección Primera, Radicación No. 930, providencia del 12 de agosto de 1988. Consejo de Estado, Sala de lo Contencioso Administrativo, Sección
Primera, Radicación No. 915, providencia del 24 de agosto de 1988.

${ }^{8}$ Ministerio del Interior y de Justicia, accesible en http://www.mininteriorjusticia.gov.co/ pagina4_detalle.asp?doc $=3 \&$ pag $=40 \&$ cat $=58$; El Consejo Superior de la Judicatura en Colombia, accesible en www.ramajudicial.gov.co/csj_ portal/assets/CIFRAS\%20DEL\%20CSJ\%20 EN\%20ELCONGRESO..doc, 2007. Consejo Nacional de Política Económica y Social, Departamento Nacional de Planeación, accesible en www.dnp.gov.co/archivos/documentos/ Subdireccion_Conpes/3172.pdf,.

${ }^{9}$ Entre otros: El Banco Interamericano de Desarrollo, en Justicia: un vínculo pendiente entre Estado, ciudadanía y desarrollo, accesible en: http://www.iadb.org/publications/IDBBooks. cfm?language=Spanish \&PARID; Transparencia por Colombia, accesible en http://www.transparencia colombia.org.co/transparencia//tabid/67/ Default.aspx e Instituto de Ciencia Política, Hernán Echavarría Olózaga, accesible en http:// www.icpcolombia.org/archivos/observatorio/ boletin_53.pdf.

${ }^{10}$ En el caso Español, como lo expresa Eduardo García de Enterría en La Batalla por las Medidas Cautelares: "Más que glosar la importancia en sí misma de una decisión de un Tribunal contencioso-administrativo que dicta, seguramente por primera vez en la historia de nuestra justicia administrativa, una "medida cautelar positiva", y que la dicta con conciencia plena de que la Constitución le obliga a ello, para poder dispensar la tutela judicial efectiva que ha sido pedida por un ciudadano, interesa me parece, detenerse un momento sobre la singu-laridad de la misma de a medida por él configurada. Debe resaltarse, por lo pronto, la simplicidad del argumento jurídico de fondo utilizado en respaldo de la técnica misma de la tutela cautelar: hay que evitar la frustración práctica del proceso, amenazado por larguísimos años de demora en la resolución y, por tanto, de la paralización virtual de la empresa la que ha denegado autorización 
para actuar, y ello es una exigencia del principio de la tutela judicial efectiva proclamado por el artículo 24 de la Constitución, con el carácter de "vinculación más fuerte"; la Sala está enteramente dispuesta a otorgar esa protección cautelar, e incluso declara que está "obligada" a ello. ¿Qué medida cautelar en concreto? El Tribunal ha dejado claro el carácter de numerus apertus de las medidas cautelares, o de su libre configuración por el juez en atención a las singularidades del caso, aunque siempre moviéndose sobre el doble parámetro de la necesidad de evitar la frustración práctica del proceso de fondo y de decidir según la "apariencia de buen derecho". Serán pertinentes (e incluso obligatorias, como hemos visto) todas las medidas imaginables que sean necesarias para atender esa doble exigencia en García de Enterría Eduardo, 1992. La Batalla por las Medidas Cautelares. Madrid, Editorial Civitas S.A. p. 222.

${ }^{11}$ De acuerdo con Luciano Parejo Alfonso "En el contexto concreto de la tutela cautelar no cabe olvidar, en efecto, las peculiaridades que singularizan la tutela judicial como tal en el orden contencioso-administrativo. Pues aquélla no es si no un elemento componente, y un elemento subordinado y servicial, de ésta. Por lo tanto, los límites del control judicial ejercitable respecto de la actividad o la actuación de la administración son de suyo límites de la tutela cautelar, toda vez que el Juez contencioso-administrativo no puede poder más en sede cautelar que en sede de tutela definitiva, Parejo Alfonso, Luciano, Derecho Administrativo, Instituciones Generales, Bases, Fuentes, Organización y Sujetos, Actividad y Control, Barcelona, Editorial Ariel S.A., 2003, pp. 1195 - 1196.

${ }^{12}$ Chiovenda, observa: "La medida provisional responde a la necesidad efectiva y actual de alejar el temor de un daño jurídico; si este daño es o no realidad inminente y jurídico resultará de la declaración definitiva", Chiovenda Giuseppe, Instituciones de Derecho Procesal Civil, Volumen I, Conceptos Fundamentales la Doctrina de las
Acciones, (Trad.)E. Gómez, Ed. Revista de Derecho Privado, Madrid,1954, pp. 319 s.s.

13 Rocco, manifiesta al respecto: "Por consiguiente, no cabe decir que la acción dirigida a obtener providencias cautelares sea mera acción, ya que no puede considerarse como accesoria del derecho cautelado, pues toda acción (de declaración de certeza, de condena o ejecutiva), y así también la acción cautelar, por ser del todo independiente del derecho sustancial al que se refiere la providencia solicitada, tiene un puro carácter de derecho procesal", Rocco, Ugo, Tratado de Derecho Procesal Civil, Volumen V, Parte Especial Proceso Cautelar, Ed. Temis, Bogotá, Desalma, Buenos Aires, 1977, pp. 24 - 25.

${ }^{14}$ Liebman expresa al respecto: "La acción cautelar está siempre vinculada por una relación de complementariedad respecto de la acción principal, ya propuesta o de la cual se anuncia la próxima proposición. Esta relación está dada por esto: que la cautela que se pide tiene la finalidad de garantizar el proficuo resultado de la acción principal. No obstante, la acción cautelar es autónoma y puede ser aceptada o rechazada según que se presente por su contenido fundada o infundada; incluso, las condiciones a las que está subordinada son diversas para cada medida cautelar, y es la doctrina la que se ha esforzado en deducir de las disposiciones de la ley un concepto unitario de las condiciones que se exijan para su aceptación. Estas condiciones son, en principio las siguientes: a) Probable existencia de un derecho, del cual se pide la tutela en el proceso principal ( funis bonis iuris); b) Fundado temor de que mientras se espera aquella tutela, lleguen a faltar las circunstancias de hecho favorables a la tutela misma ( periculum in mora)", Liebman, Tulio, Manual de Derecho Procesal Civil, (Trad.)Santiago Sentis Melendo, Ediciones Jurídicas Europa-América, Buenos Aires, 1980,pp. 161 - 164.

${ }^{15}$ Consejo Nacional de Política Económica y Social, Departamento Nacional de Planeación, accesible en www.dnp.gov.co/archivos/ documentos/Subdireccion_Conpes/3172.pdf 


\section{Referencias}

Azula, J. (1982). Manual de Derecho Procesal, Teoría del Proceso, Tomo I. (p. 69). Bogotá: Editorial A B C.

Bacigalupo, M. (1999). La Nueva Tutela Cautelar en el Contencioso Administrativo. (pp.8 ss) Madrid-Barcelona: Marcial Pons, Ediciones Jurídicas y Sociales S.A.

Carnelutti, F. (1944). Sistema de Derecho Procesal Civil I, Introducción y Función del Proceso Civil. (p. 242). Buenos Aires: Unión Tipográfica Editorial Hispano Americana.

Calamandrei, P. (1945). Introducción al Estudio de las Providencias Cautelares. Traducción de Santiago Sentis Melendo. (p. 83). Buenos Aires: Editorial Bibliográfica Argentina.

Chinchilla, C. (1991). La Tutela Cautelar en la Nueva Justicia Administrativa. (pp. 42-55). Madrid: Editorial Civitas S.A.

Constitución Política de Colombia (2007). Bogotá: Editorial Legis.

Chiovenda, G. (1954). Instituciones de Derecho Procesal Civil, Volumen I, Conceptos Fundamentales la Doctrina de las Acciones, Traducción de E. Gómez. (pp. 319) Madrid: Editorial Revista de Derecho Privado.

De la Sierra, S. (2004). Tutela Cautelar Contencioso Administrativa y Derecho Europeo. (p.42-43). Cizur Navarra: Editorial Aranzadi S.A..

Devis, H. (1983). Compendio de Derecho Procesal Tomo I. Teoría General del Proceso. (p.209). Bogotá : Editorial ABC.

García de Enterría, E. (1992). La Batalla por las Medidas Cautelares. (p. 222). Madrid: Editorial Civitas S.A.
García de Enterría, E. (2000). Democracia, Jueces y Control de la Administración. Quinta Edición. (pp. 256 y ss). Madrid: Editorial Civitas S.A..

García de Enterría, E. y Fernández, T.(1997). Curso de Derecho Administrativo II. (p. 622). Madrid: Editorial Civitas S.A.

García, E. (1981). Medidas Cautelares, Introducción a su estudio. (p. 12). Bogotá: Editorial Librería El Foro de la Justicia.

Ibáñez, J. (2007). Estudios de Derecho Constitucional y Administrativo. (p. 819) Bogotá: Justicia y Desarrollo Sostenible, Legis y Universidad Sergio Arboleda.

Ibáñez, J. (1985). Antecedentes del Código Contencioso Administrativo. Tomo I. (pp. 93-107). Proyecto de ley presentado por el Doctor Hugo Palacios Mejía a consideración del Congreso en las sesiones ordinarias de 1980 y Radicado con el No.25 en la Cámara de Representantes.

Liebman, T. (1980). Manual de Derecho Procesal Civil. Traducción Santiago Sentis Melendo. (pp. 161 - 164). Buenos Aires: Ediciones Jurídicas Europa-América.

Moreno, L. (2000). Acceso a la Justicia. (pp. 108 - 122). Bogotá: Ediciones Academia Colombiana de la Jurisprudencia.

Nieto, A. \& Gordillo, A. (2003). Las Limitaciones del Conocimiento Jurídico. (p. 24). Madrid: Editorial Trotta.

Restrepo, M. (2005). La Necesidad de Ampliar la Tutela Cautelar Judicial en el Proceso Contencioso Administrativo. Saberes, Revista de Estudios Jurídicos, económicos y sociales, (Volumen 3, Separata. pp. 17 18). Madrid: Universidad Alfonso X el Sabio.

Rocco, H. (1977). Tratado de Derecho Procesal Civil. Volumen V. Parte Especial 
Proceso Cautelar. (pp. 24 y 25). Bogotá, Desalma, Buenos Aires: Temis.

Parejo, L. (2003). Derecho Administrativo, Instituciones Generales, Bases, Fuentes, Organización y Sujetos, Actividad y Control. (pp. 1195-1196). Barcelona: Editorial Ariel S.A.

\section{Consultas en línea}

Banco Interamericano de Desarrollo (2007). En: Justicia: un vínculo pendiente entre Estado, ciudadanía y desarrollo, Extraído: mayo 11 de 2008 desde http://www.iadb.org/publications/ IDBBooks.cfm?language=Spanish\&PARID

Consejo Nacional de Política Económica y Social, Departamento Nacional de Planeación (2003). Extraído 11 de mayo de 2008 desde www.dnp.gov.co/archivos/documentos/ Subdireccion_Conpes/3172.pdf

Consejo Superior de la Judicatura en Colombia (2007). Extraído 12 de mayo de 2008 desde www.ramajudicial.gov.co/csj_portal/assets/ CIFRAS \% 20DEL\%20CSJ\% 20EN\% 20 ELCONGRESO..doc

Constitución Política de la República de Chile (2008). Extraído 11 mayo de 2008 desde http://www.camara.cl/legis/constitucion/ contitucion_politica.pdf

Constitución de España. (2008). Extraído 11 de mayo de 2008 desde http://constitucion .rediris.es/legis/1978/ce1978.html

Constitución de Italia. (2008). Extraído 11 de mayo de 2008 desde http://es.camera.it/ deputati/funzionamento $2002 / 03$. costituzione.asp

Constitución Política de los Estados Unidos de Mexicanos (2008). Extraído 11 de mayo de 2008 desde http://info4.juridicas.unam.mx/ ijure/fed/9/

Convención Americana de Derechos Humanos, Pacto de San José de Costa Rica, artículo 8.1 (2008). Extraído 11 de agosto de 2008 desde http://www.oas.org/Juridico/spanish/ tratados/b-32.html.

Declaración Universal de Derechos Humanos. Artículo 8 (2008). Extraído 11 de agosto de 2008 desde http://www.un.org/spanish/ aboutun/hrights.htm

Instituto de Ciencia Política, Hernán Echavarría Olózaga, Extraído el 11 de agosto de 2006 desde http://www.icpcolombia.org/archivos/ observatorio/boletin_53.pdf.

Ley Fundamental para la República Federal Alemana. Extraído el 11 de agosto de 2006 desde http://www.estudionuner.com.ar/ calemana.htm

PNUD (2004). Informe Anticorrupción. Extraído el 20 de junio de 2008 desde http:// www.undp.org/governance/docs/ AC_PN_Spanish.pdf

Transparencia por Colombia. Extraído el 11 de mayo 2008 desde http://www.transparencia colombia.org.co/transparencia//tabid/67/ Default.aspx 